\title{
Best Practices for Onsite Wastewater System Inspections, Maintenance and Record Keeping in the Lake Simcoe Watershed
}

\author{
Cameron Curran, MSc Candidate \\ Dr. John FitzGibbon, Professor

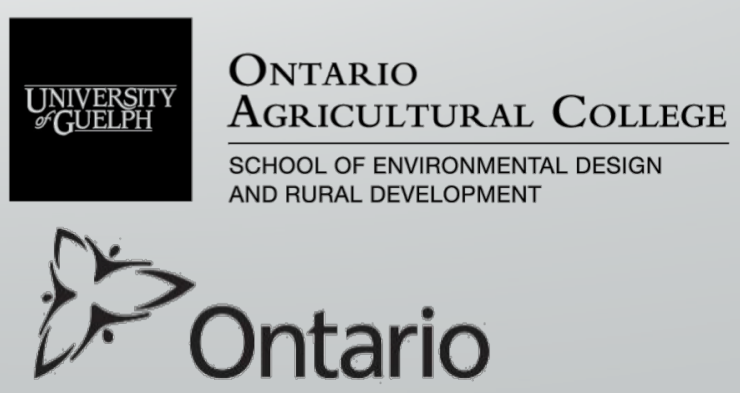




\section{Presentation Overview}

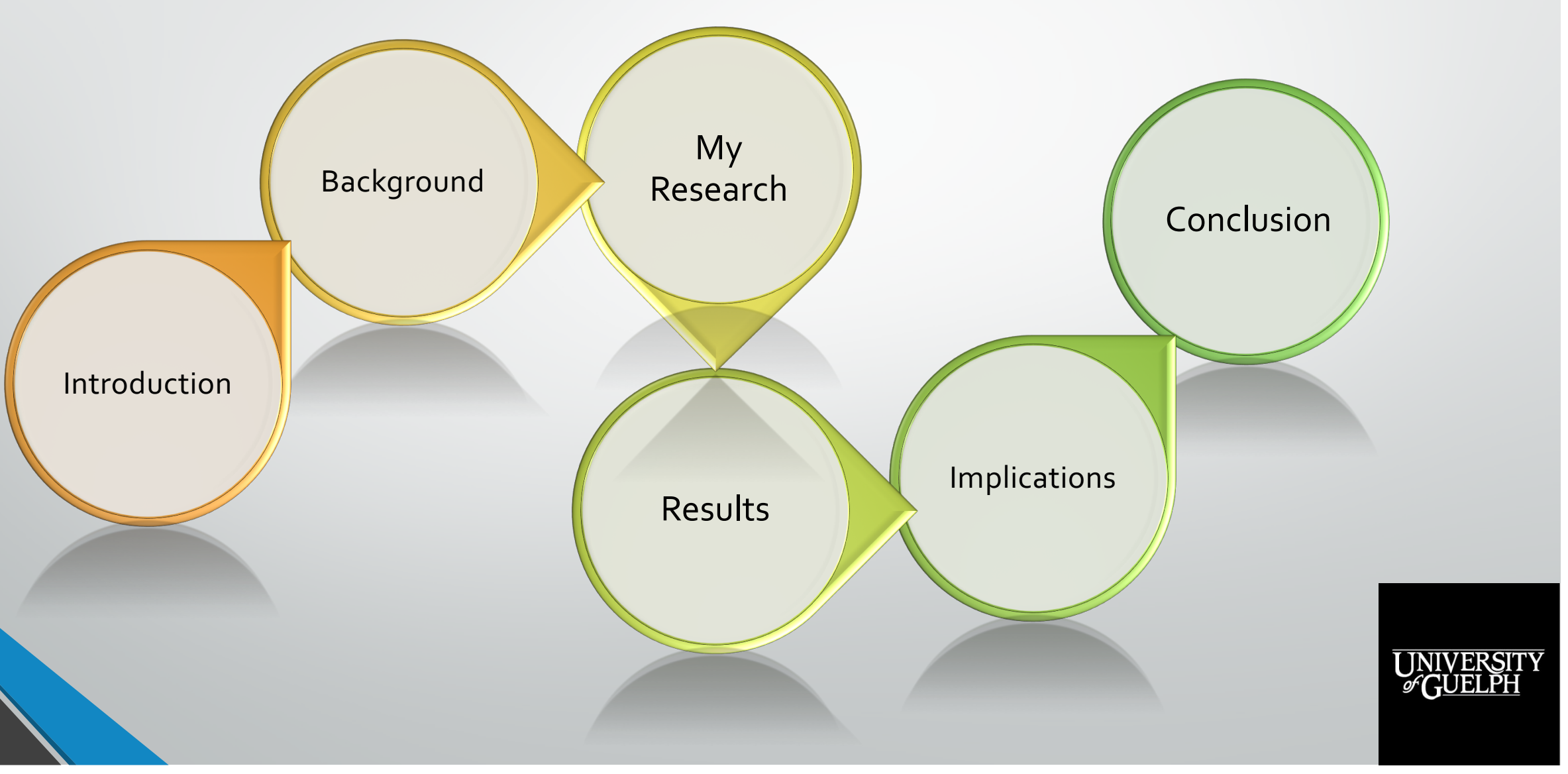




\section{Introduction}

- Healthy lakes mean social, environmental and economic prosperity for our Province.

- Waters are threatened by private rural onsite wastewater (septic) systems, through phosphorus loading

- Out of sight, out of mind mentality.

- Reinspection programs are inconsistently managed

- Opportunity for collaborative management of programs: government and local communities 


\section{Background}

What we know:

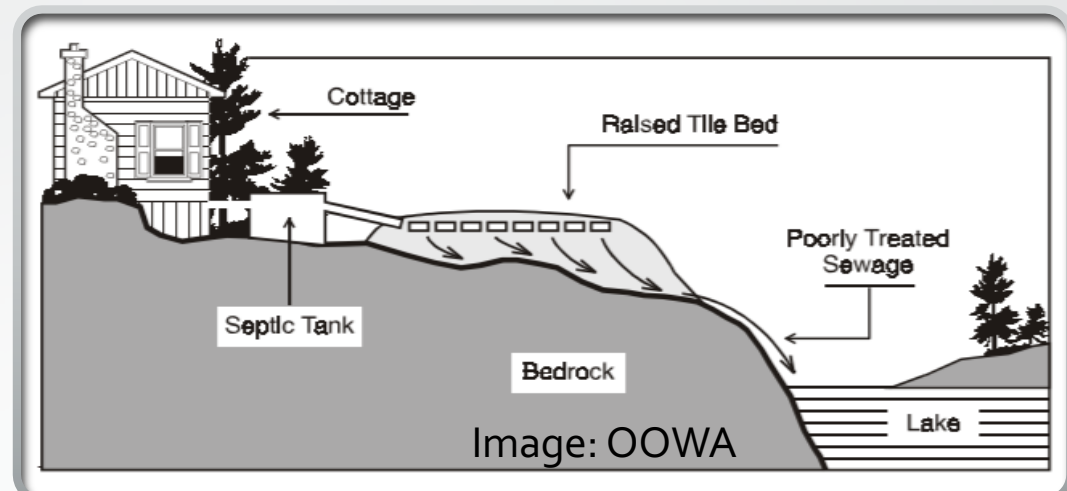

- 2012 Ontario Building Code (O.Reg 315/10)

- Mandatory septic reinspections

- Onsite septic systems within 10om of Lake Simcoe surface waters and all provincial source protection areas

- Reinspections contribute to lake and groundwater protection

- Human and environmental health

- Lake Simcoe Protection Plan

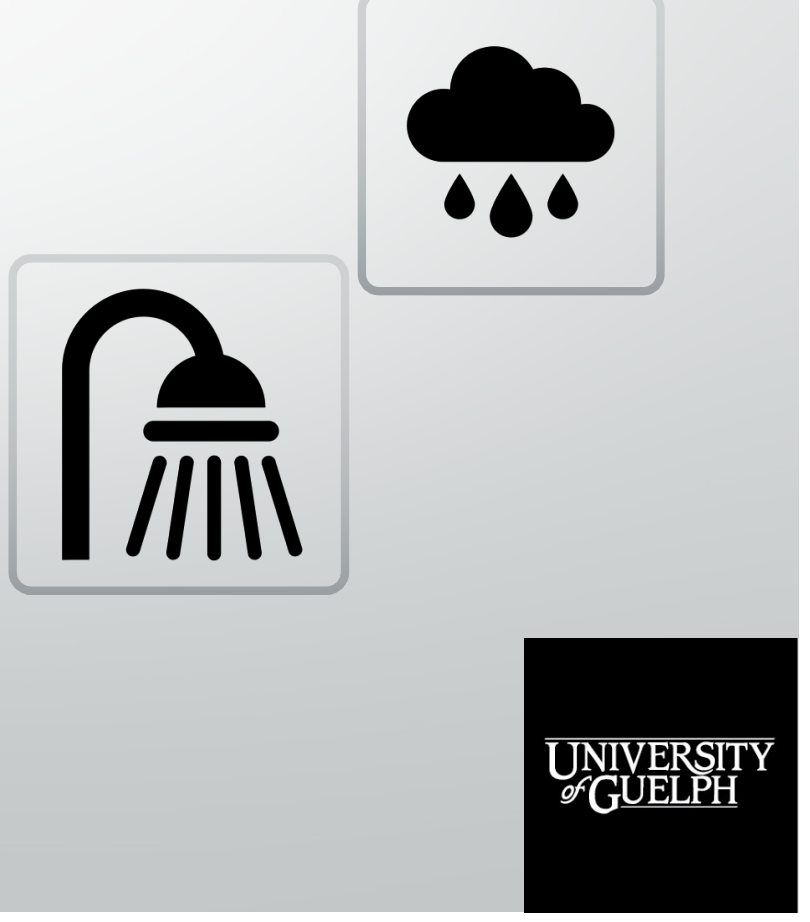




\section{My Research}

- Addresses the quality of septic system reinspection programs

- Semi-structured interviews

- Collaboration as a framework for Environmental Stewardship/Capacity Building

- Improve the capacity for Principal Authorities, within environmentally vulnerable areas, to adopt provinciallystandardized best practices for septic reinspections in the Lake Simcoe Watershed

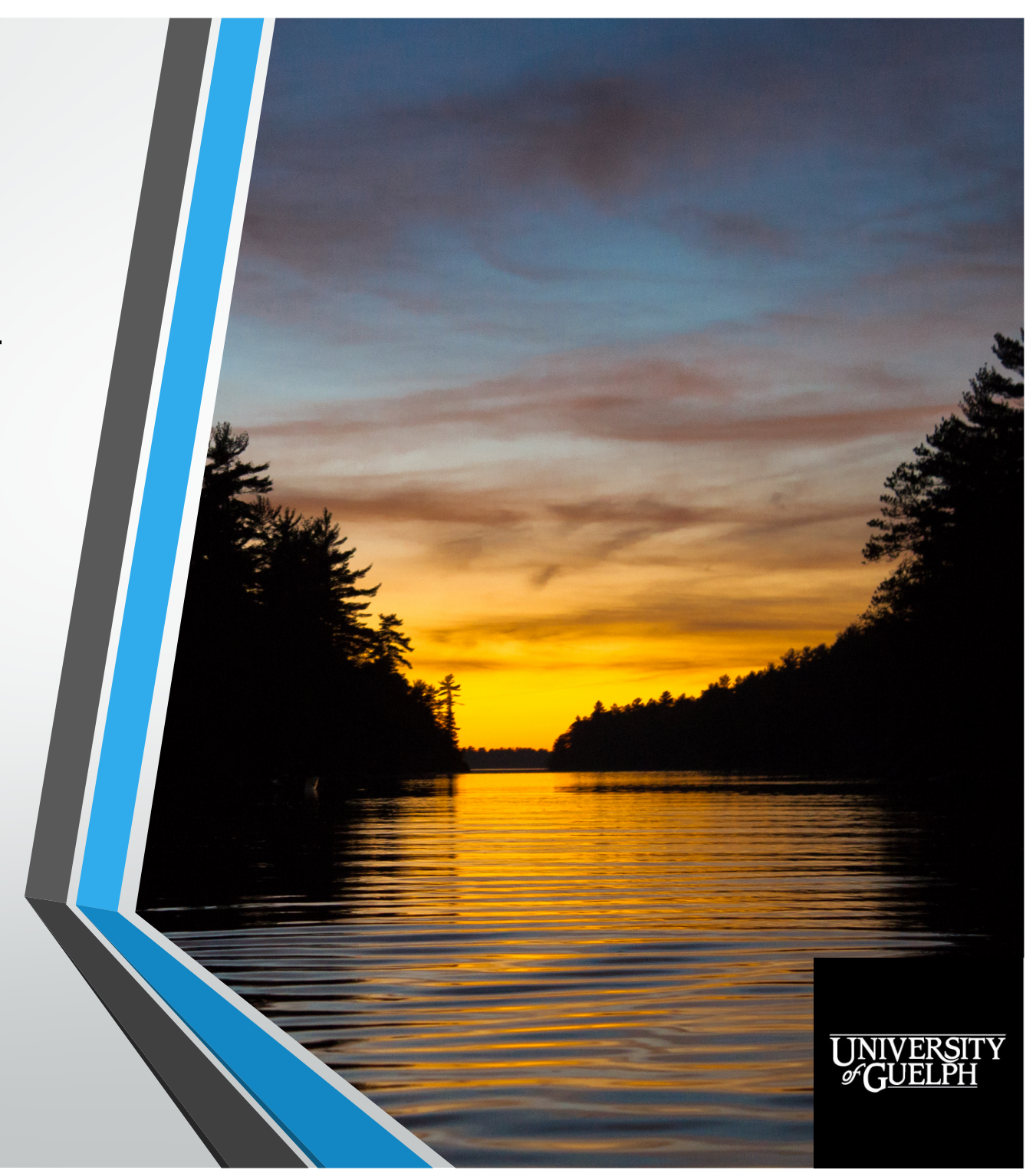




\section{Research Goals}

- Jurisdictional scan of best practices within the Great Lakes region of Canada and the U.S.A.

- Identify reinspection program administrators' perceptions of intra-provincial program support

- Assess level of awareness of home or system owner regarding their onsite septic system

- Propose a best practice, collaboration-based framework for septic reinspections in Ontario

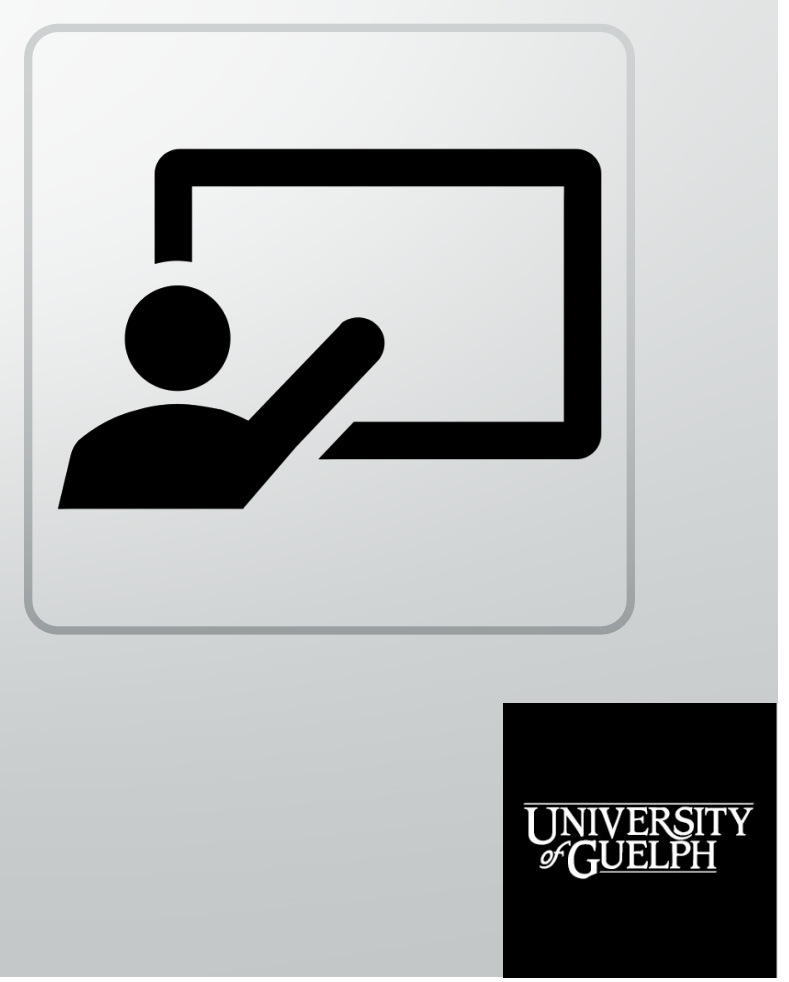



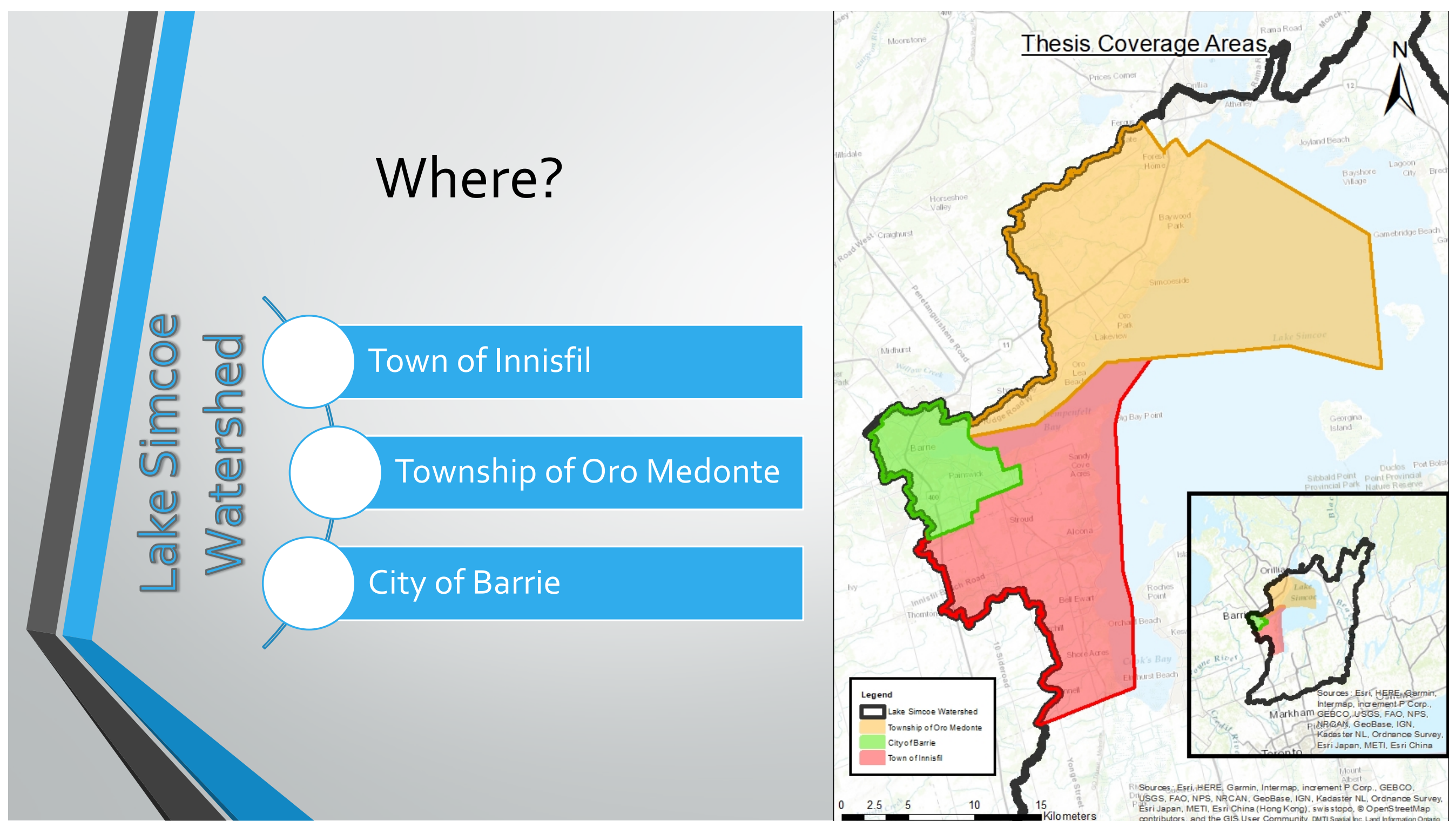


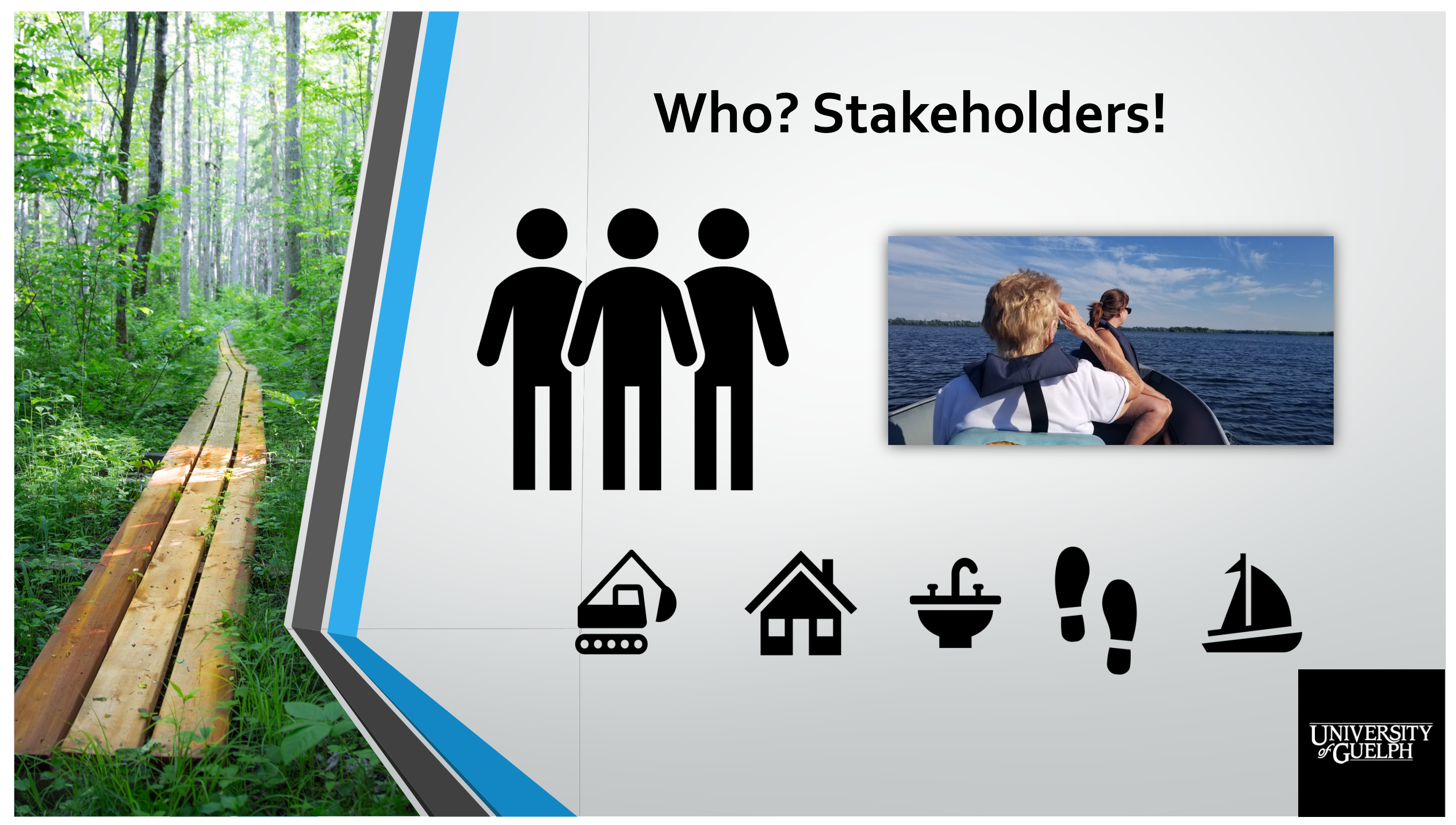




\section{Preliminary Results}
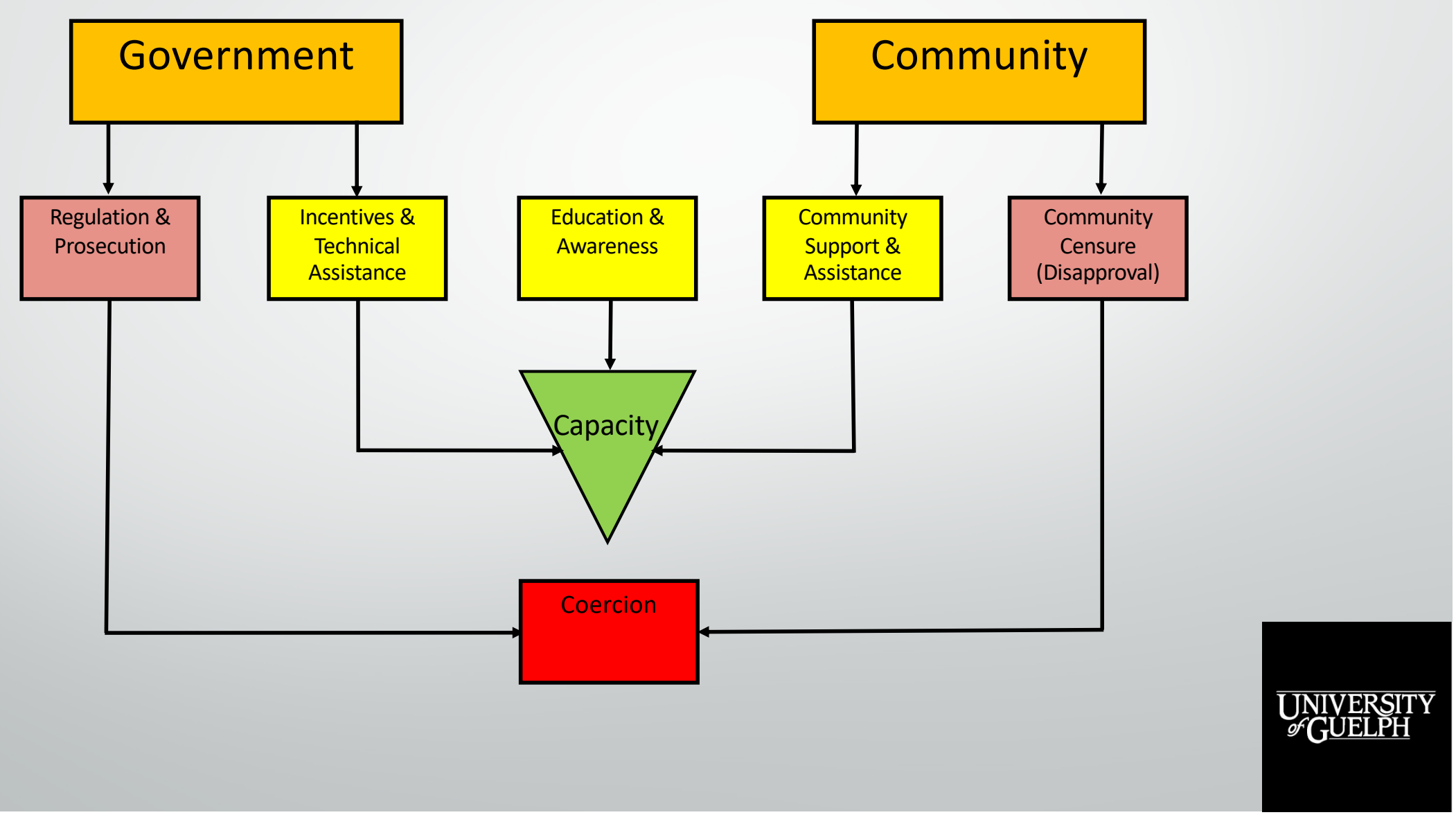


\section{Implications}

- A collaborative management approach will allow governments and local communities to efficiently work towards common goals

- Improved modelling forecasts for phosphorus loading within watersheds

- Opportunities for future generations to enjoy safe and healthy lakes

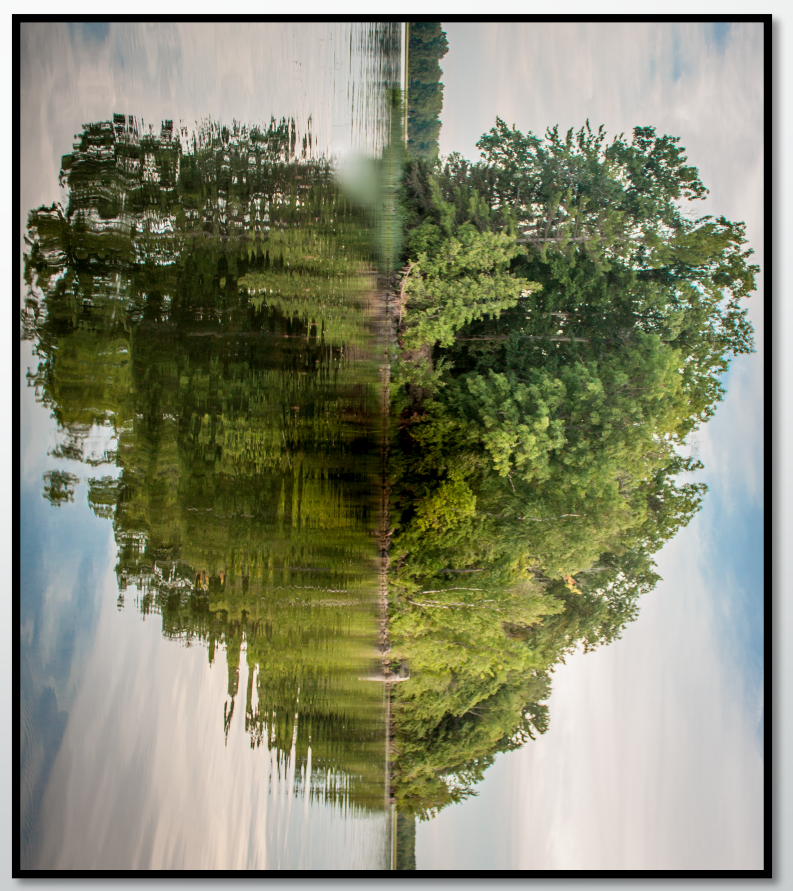




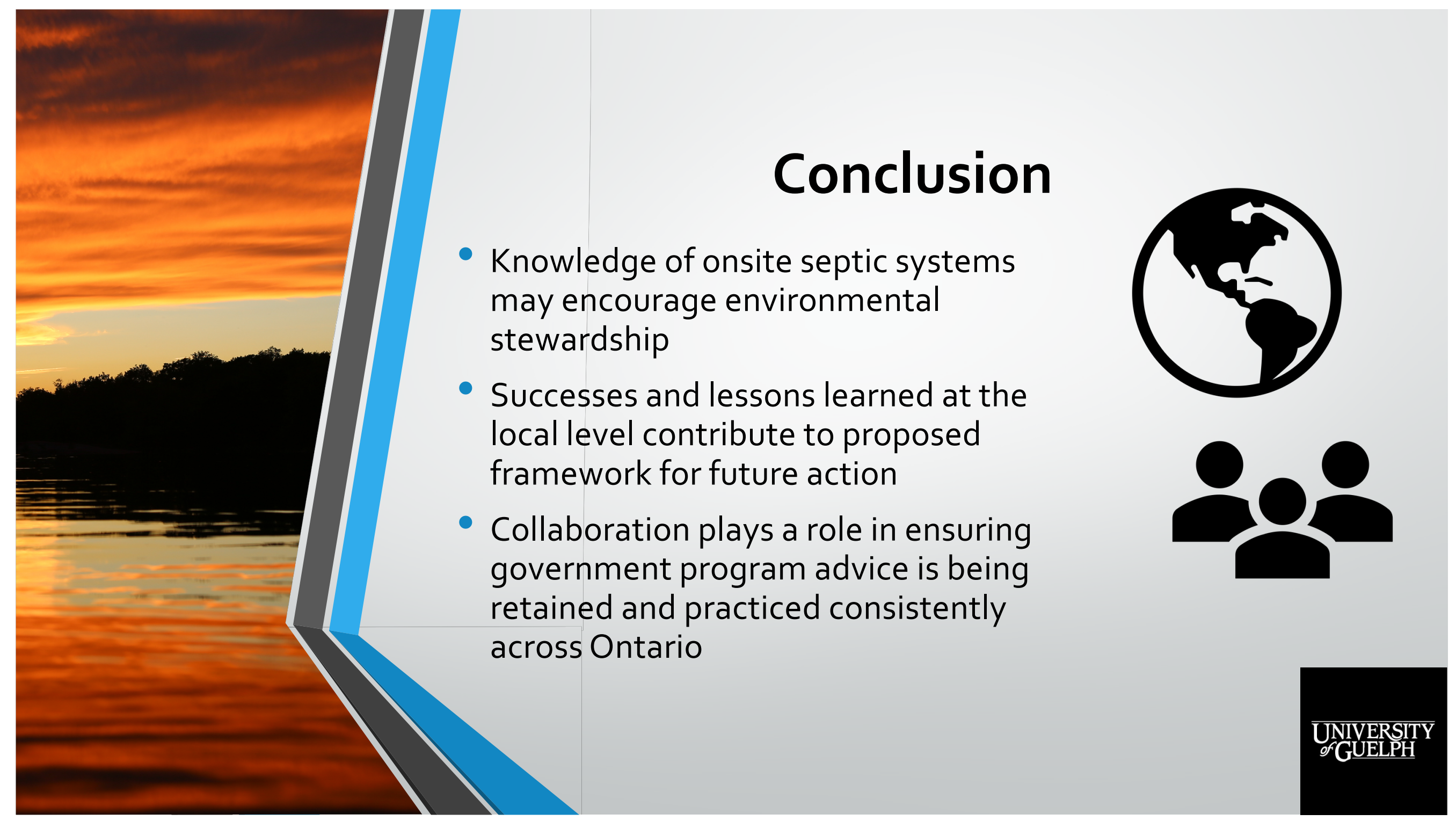




\title{
Thank you
}

\author{
Questions?
}

\section{Cameron Curran ccurrao2@uoguelph.ca}

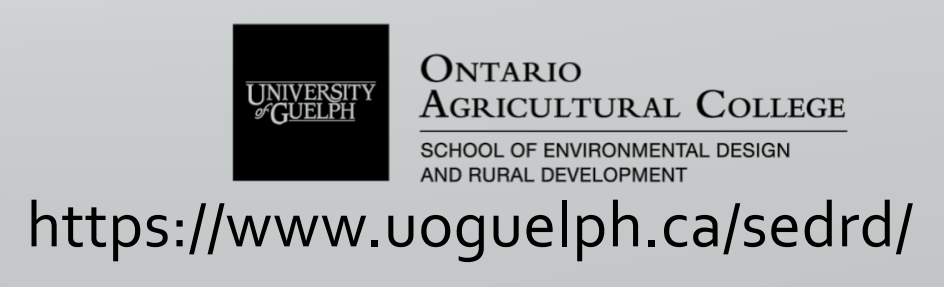

